\title{
Archetype definition for analysing retrofit solutions in urban areas in Europe
}

Michele De Carli ${ }^{l}$, Laura Carnieletto ${ }^{l}$, Antonino Di Bella ${ }^{l}$, Samantha Graci $^{l}$, Giuseppe Emmi ${ }^{l}$, Angelo Zarrella ${ }^{l}$, Nicola Baseggio $^{1}$, Marco Belliardi ${ }^{2}$, Leonardo Rossi ${ }^{3}$, Luciano Mulè Stagno ${ }^{4}$, Borja Badenes ${ }^{5}$, Javier Urchueguía ${ }^{5}$, Burkhard $^{7}$ Sanner ${ }^{6}$, Gianluca Cadelano $^{7}$, Adriana Bernardi $^{7}$

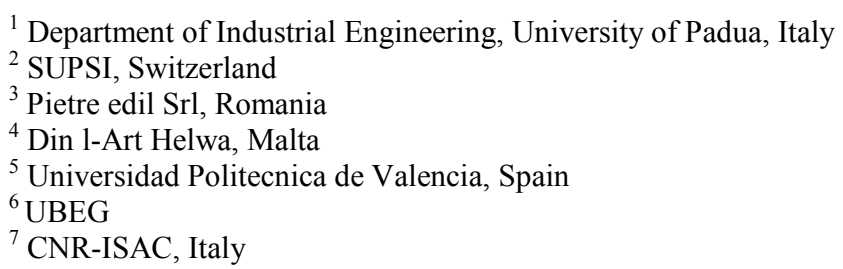

\begin{abstract}
Ground Source Heat Pumps (GSHP) are gaining interest for many applications and a very difficult task is to look at their affordability in urban environments with limited spaces. For this reason, the EU project GEO4CIVHIC has been funded. In order to set up different cases with different levels of retrofit and try to generalize results, the project focuses the activity on archetypes, i.e. buildings which may represent the usual type of building which may be found more frequently in urban environments around Europe. The analysis of the archetypes has been based on literature review and analysing the existing databases of buildings in Europe. The work allowed to determine a reference building for single family house and a building representing an apartment block for multi-users. In this latest case two types of possible uses have been examined: residential building and office building. In order to set up different levels of retrofit and cost-effective solutions, three different climates have been defined: warm climate, mild climate and cold climate. The climatic conditions do not only affect the energy demand of the building and the peak power needed for heating and cooling, but also determine different ways of buildings' construction and define different levels of insulation. Last but not least, the buildings have been also subdivided into existing buildings, i.e. built up from 1960 to 2000 and historic buildings, i.e. buildings earlier than 1960 . The paper presents the first step of the research which permitted to define the different archetypes, their dimensions and way they are constructed. Moreover, the different simulations allowed to define the energy needs of the buildings as well as the peak power for heating and cooling. This allows to create a matrix for the different levels of retrofit solutions which will be associated to related costs for a cost-benefit analysis to check the most achievable solutions.
\end{abstract}

\section{Introduction}

As well known, buildings represent $40 \%$ of $\mathrm{CO}_{2}$ emissions in Europe. Among them, 70\% are residential buildings and 30\% are commercial buildings. Most of the buildings which need to be renovated are in urban areas; in particular, Figure 1 shows the case of the Province of Padua, that is generally representative and common for all Europe.

The H2020 project GEO4CIVHIC (Most Easy, Efficient and Low-Cost Geothermal Systems for Retrofitting Civil and Historical Buildings) aims at destroying the barriers and increasing the market of Ground Source Heat Pumps in the retrofit of buildings in urban environments [1]. For doing this several actions are needed, for example one of the most important is finding rules to generalize the results and general solutions in terms of costs and benefits, both from economic and environmental points of view.

A first issue is the space availability for installing the borehole field for a GSHP installation, which is crucial due to the standard dimensions of a common borehole field and to the limited space in a common urban situation. In many cases the space availability will depend not only in already existing free space as gardens, parking lots, etc., but also in the level or intensity of the refurbishment actuation (higher levels will probably mean more possibilities for drilling). An analysis of the usual layout of urban environments has been set up, in order to answer to questions on limitations for installing GSHP systems in the urban area. Depending on the layout of the city, there might be

Corresponding author: author@e-mail.org 
buildings with small internal courtyards or even with gardens. As an example, two city-centres in the same climatic area in North of Italy are shown in Figure 2: Ferrara (a) and Padua (b). It can be seen that Ferrara has few and narrow patios, while Padua has internal wide courtyards with even large gardens, excluding the oldest part of the city. Although Figure 2 represents cities of North of Italy this is a general rule in Europe.

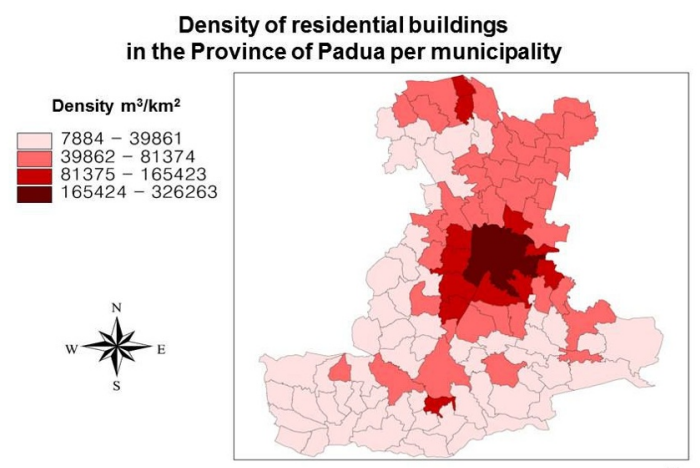

Fig. 1. Density of volume of residential buildings per surface area in the different municipalities in the Province of Padua

a

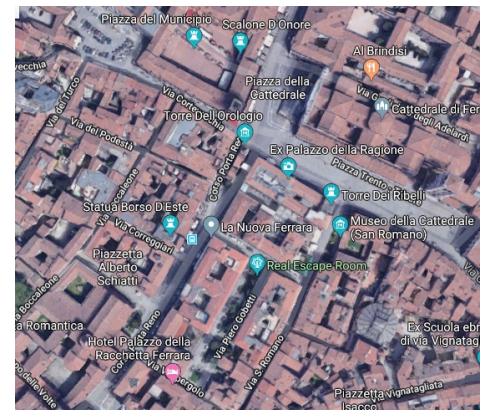

b

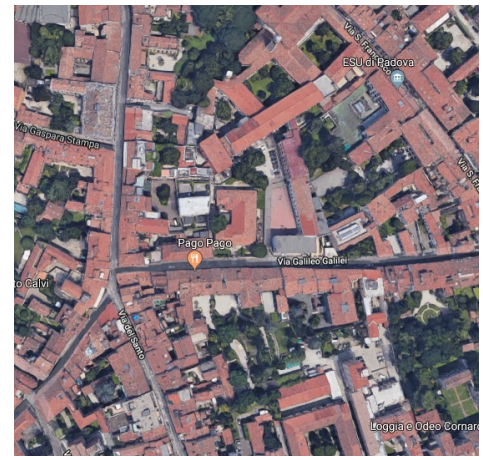

Fig. 2. Example of different aerial view of two different urban contexts: Ferrara (a) and Padua (b) in Italy.

It is hence important to define archetypes inside urban environments to check better the barriers and how to solve problems in the built environment. These archetypes have to represent in a proper way the most common typology of buildings in the urban areas in all countries of Europe.

Beside that it is also important to define which level of retrofit can be done (shallow and deep) related to the envelope and/or the HVAC.

The present work represents the first step of the project activities, which is the definition of the archetypes and possible HVAC solutions. The definition of the available space for looking at the installation possibilities in the surroundings is very important when looking at the GSHP technology, but it is a further step which is currently under investigation and hence will not be shown in the present paper.

\section{Building types definition}

The first step has been checking existing literature on the building sector and seeing the average consumptions of buildings. The energy demand of existing buildings around Europe ranges from $150 \mathrm{kWh} /\left(\mathrm{m}^{2}\right.$ year $)$ to 300 $\mathrm{kWh} /\left(\mathrm{m}^{2}\right.$ year $)$ based on recent studies [2]. Hence there is a big potential in Europe, estimated in about $25,000,000,000 \mathrm{~m}^{2}$ of floor area. The $40 \%$ of existing buildings has been built up before 1960 .

Since the aim of the work is to increase the use of GSHPs in the built environment in retrofitting buildings, the different types of buildings, their age as well as the possible HVAC solutions have to be considered.

A first subdivision may be done by dividing into historic and non-historic. It is not simple to define when a building is historic and when not, because there is not a unique definition. There are two standards trying to define historical buildings. The first one is the FprEN 16883 [3] which underlines the difference between a historic building and building of heritage significance. A historic building does not necessarily have to be statutorily designated as cultural heritage. A historic building is a specific form of objects, as defined in EN 15898 [4], which is single manifestation of tangible cultural heritage. The term "object" is used in the standard for cultural heritage, both immovable and movable. In specific professional contexts, other terms are used: e.g. "artefact", "cultural property", "item", "ensemble", "site", "building", "fabric".

In general, a building with more than 50-70 years life is usually considered as historic even though it is not particularly or significantly important from the architectural point of view. Since the aim of the project is to look at the retrofit of the buildings (both shallow and deep retrofit) in the urban environment and since we are conscious that in the next future deep retrofit will be the common rule to refurbish buildings, for simplicity we will name "existing buildings" the ones which are neither historical nor buildings of heritage significance, and we will name "historical" the ones where only partial retrofit can be made. As criterion to select when to consider a building existing or historic, it has been decided to consider buildings built before 1960 to be "historic" and buildings built after 1960 as "existing".

A second subdivision is related to the use of the buildings. Since the projects is addressed to urban environments, the types of users are mainly two: residential and commercial users. Since the commercial users may be of different types (e.g. offices, shops, hotels, etc.), it has been decided to look at the office buildings besides the residential buildings.

The last point is to identify the number of users, since buildings may be single-users or multi-users. The HVAC plant technology changes usually if there are different owners/users, like in the block of flats, or if there is only 
one user/owner, as in the case of single-family house or detached house. For this reason, it has been decided to look at two possible cases: a multi-user building and a single-user building.

Finally, the emitters have to be considered accordingly, since the project proposes GSHP solutions eventually combined with air-to-water reversible heat pumps. Hence the temperature levels at which the water operates in the building is also important and must be considered. This particular item is under investigation but it is not covered in the present paper because so far the work focused on the definition of the archetypes and the estimation of their net energy demands.

In conclusion, the climatic conditions have to be chosen to cover most of the climatic conditions in Europe. For doing this, the previous project results [5] have been considered as starting point for the climates. A statistical analysis has been set up among the weather conditions which are considered for the standardized seasonal efficiency of the heat pumps in the EN 14825 [6] standard, i.e. Athens (warm climate), Strasburg (mild climate), Helsinki (cold climate). The analysis performed based on degree-days for heating (DHH) and for cooling (DDC) shows that the three cities are representative of the climate for each considered macro-area, since the three considered locations are within the range of the standard deviation (Figure 3).

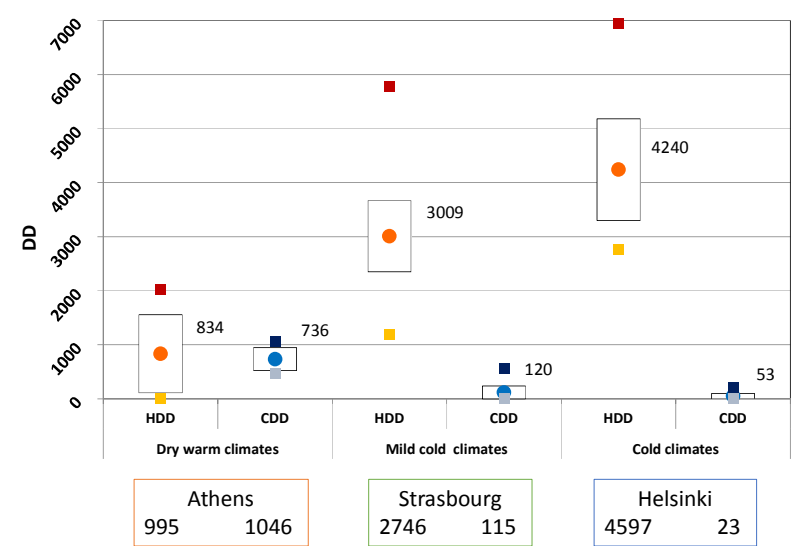

Fig. 3. Analysis for selecting the climatic conditions to be considered in the energy analysis of the archetypes.

\section{Archetypes definition}

Building typologies are different due to the age of construction as well as the possible use in urban context. As a matter of fact, most of the buildings have been built before any regulation or restriction on the energy consumption in buildings.

It is important to have reference buildings in order to understand the most diffuse construction types in order to get information on the possible solutions which can be proposed together with GSHP. From this point of view two sets of databases have been considered since they represent a good basis for the analysis of the state of art of buildings in Europe. The first one is based on a COST action; the other is based on two related European projects.

The first project considered is the COST action TU0901 "Integrating and Harmonizing Sound Insulation Aspects in Sustainable Urban Housing Constructions" [7], in which were involved around 90 experts from 29 European countries. The aim of the project was to establish a common framework in building acoustics throughout Europe studying of regulatory sound insulation requirements for dwellings and classification schemes existing in several countries.

A general focus on energy savings and sustainable constructions has in some cases led to the development of constructions with potentially significant acoustic problems. On the other hand, the large variety of housing types, construction techniques and common building materials do not allow generalizing the interaction between thermal and acoustics problems.

To consider the housing stock in Europe in relation to sound insulation, different types of sound transmission and the proportion of occupants which may experience sound transmission, a reference database was defined collecting the most common type of housing and construction methods found in each country. Using a combination of Eurostat statistics (2013) and information gathered during COST Action TU0901, the proportion of population which inhabit detached housing, attached (row/terraced, semi-detached) housing or apartment (flatted) housing was described. For these building types, information on building techniques were also been collected, both from sound insulation and from energy saving point of view.

The second project that collects existing building types across Europe is the EU project TABULA - EPISCOPE [8] where a database of building typical consumptions has been set up. EPISCOPE provides a huge amount of combinations of residential buildings and HVAC systems including NZEB buildings. The database provides the energy performance assessment before and after renovation, accounting actions both on the envelope and on the plant. The project TABULA - EPISCOPE is based on National criteria according to the building and plant features and to the weather conditions. The results are the overall consumptions of the buildings.

The starting point has been to investigate the database of the project TABULA-EPISCOPE, an international database for residential buildings which considers 21 European countries. Different buildings envelope characteristics are listed at national level as a function of the year class, i.e. the year the building has been built up. Four different building typologies are present in the database: apartment block, single family house, multifamily house, terraced house. Different parameters have been considered, such as opaque envelope and window $\mathrm{U}$-values, S/V ratio, glazed surface/floor area ratio.

The main objective of the analysis has been the definition and the assessment of proper buildings archetypes according to European building stock in an urban context in order to apply geothermal energy in city centres. Looking at the urban environment, the analysis has shown that the main representative types of buildings are linear buildings (Figure 4) which can be subdivided 
in two main archetypes in all representative locations considered for the climates: the apartment block (Figure 5.a) and the terraced house (Figure 5.b).

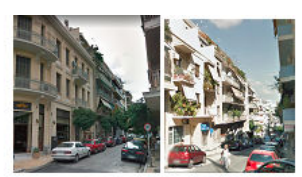

a

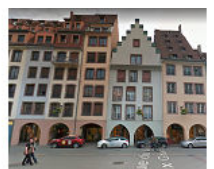

b

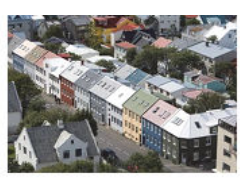

c
Fig. 4. Examples of linear buildings architecture in the three considered climates: Athens (a), Strasburg (b), Helsinki (c)

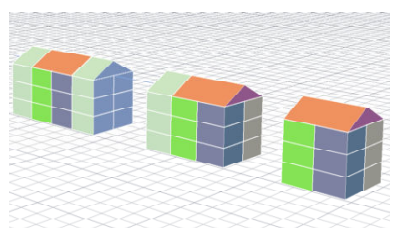

$\mathbf{a}$

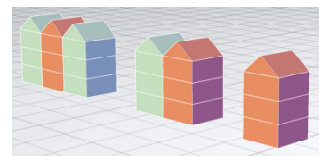

b
Fig. 5. Example of possible solutions for apartment blocks (a) and terraced house (B)

A statistical analysis has been performed, taking into account the main characteristics of the buildings (geometry and thermal characteristics of the envelope) by grouping the data of TABULA in the macroareas, i.e. warm (Cfa and Csa as Köppen-Geiger scale), mild (Cfb) and cold climate (Dfb). In this way average values for the main geometrical characteristics and envelope Uvalues have been estimated, as shown here below.

\subsection{Apartment blocks}

According to statistical data coming from TABULA database, a 5-floor building has been selected to be considered as reference building for the apartment block solution.

Standard height for the ceiling in existing buildings has been set equal to $2.5 \mathrm{~m}$, while in historical buildings an average height of about $3.15 \mathrm{~m}$ has been considered ( $25 \%$ higher than the height of existing buildings). The glazed/net floor surface ratio has been found to be typically in the range $12-24 \%$, hence $19 \%$ as average value has been considered in existing buildings. In historical buildings an increased glazed surface has been considered according to the corresponding ceiling height, i.e. $22 \%$ as ratio between the glazed area and the net floor area. The main parameters resulting from the statistical analysis are reported in Table 1.
Table 1. Average values for the main geometrical parameters considered for the archetypes in the case of existing buildings

\begin{tabular}{|c|c|c|c|c|}
\hline \multicolumn{2}{|c|}{ Building type } & $\begin{array}{c}\text { Gross } \\
\text { Volume }\end{array}$ & $\begin{array}{c}\mathbf{A}_{\text {glazed }} / \mathbf{A}_{\text {floor }} \\
{[-]}\end{array}$ & $\begin{array}{l}\text { Net Floor } \\
\text { Area per }\end{array}$ \\
\hline \multirow{2}{*}{ 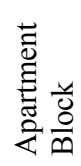 } & Existing & 5825 & 0.19 & $82 *$ \\
\hline & Historical & 7125 & 0.23 & $82 *$ \\
\hline \multirow{2}{*}{ 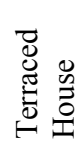 } & Existing & 500 & 0.17 & 138 \\
\hline & Historical & 610 & 0.21 & 138 \\
\hline
\end{tabular}

*average value between $94 \mathrm{~m}^{2}$ (2 bedrooms) and $70 \mathrm{~m}^{2}$ (1 bedroom)

Figure 6 shows the geometry and the layout of the residential plan, representing the multifamily archetype. The office building has been considered with the same configuration with 4 offices of the same size of the apartments.

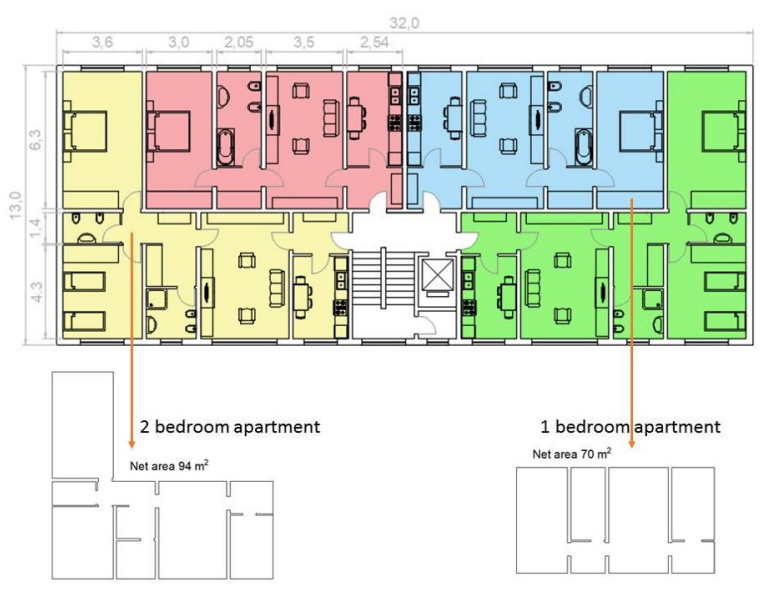

Fig. 6. Lay-out of the general floor for the multi-user apartment block

\subsection{Terraced House}

Existing and historical single-family buildings have been considered as linear terraced houses. According to statistical data coming from TABULA database, a 3 floor building has been considered:

The standard height for ceiling and the glazed/net floor surface ratio has been considered the same as the apartment blocks. The main parameters resulting from the statistical analysis are reported in Table 1 also for the terraced house. In Figure 7 the geometry and the layout of the terraced house are reported. In this case the building has been considered only residential. 


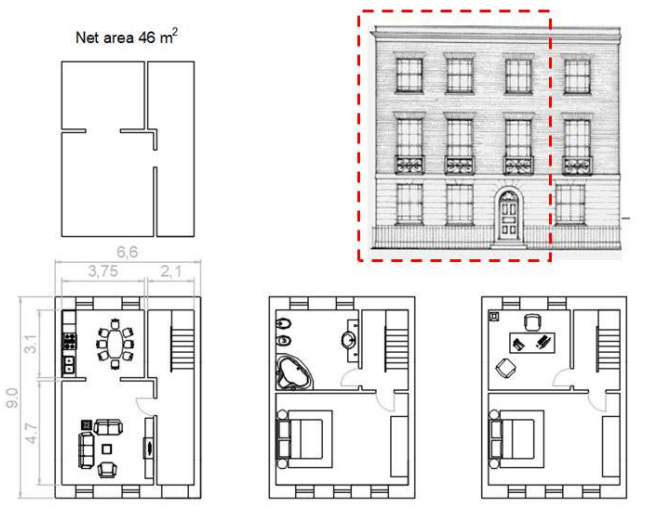

Fig. 7. Layout of the single-family terraced house

\subsection{Thermal characteristics of the buildings}

An analysis of the envelopes has been carried out among the different types of buildings and age as a function of the climate. Constructions' data and related thermal characteristics have been considered taking into account the climate and similar building techniques. As a result, the reference values for existing buildings and historical buildings are shown in the Table 2 , verifying that the colder the climate the lower the transmittance.

Since the aim of the project is to look at the possible retrofit of buildings, an analysis based on current local limiting values for the U-values of the envelope (opaque and glazing surfaces) has been carried out in all the countries involved in the project, asking also additional information in some specific countries which could not be covered by the partners (e.g. Scandinavian countries).

Table 2. Average U-values based on the statistical analysis on TABULA database.

\begin{tabular}{|c|c|c|c|c|c|c|}
\hline $\begin{array}{c}\text { Building } \\
\text { type }\end{array}$ & Age & Climate & Roof & Walls & Floor & $\begin{array}{l}\text { Win- } \\
\text { dows }\end{array}$ \\
\hline \multirow{6}{*}{ 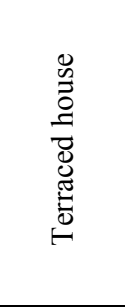 } & \multirow{3}{*}{ existing } & warm & 1.65 & 0.89 & 1.36 & 3.55 \\
\hline & & mild & 0.70 & 1.05 & 1.01 & 2.85 \\
\hline & & cold & 0.29 & 0.35 & 0.41 & 2.35 \\
\hline & \multirow{3}{*}{ historical } & warm & 2.30 & 1.75 & 1.29 & 4.97 \\
\hline & & mild & 1.19 & 1.75 & 1.38 & 3.69 \\
\hline & & cold & 0.54 & 1.11 & 0.79 & 2.72 \\
\hline \multirow{6}{*}{ 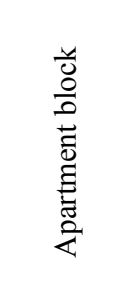 } & \multirow{3}{*}{ existing } & warm & 0.79 & 0.79 & 1.15 & 3.90 \\
\hline & & mild & 0.82 & 1.01 & 0.68 & 2.93 \\
\hline & & cold & 0.13 & 0.22 & 0.16 & 1.43 \\
\hline & \multirow{3}{*}{ historical } & warm & 1.76 & 1.35 & 1.07 & 5.19 \\
\hline & & mild & 1.80 & 1.81 & 0.95 & 3.41 \\
\hline & & cold & 0.32 & 0.59 & 0.66 & 2.50 \\
\hline
\end{tabular}

\section{Energy simulations}

The two archetypes have been hence considered as existing building and historical buildings. The multi-user building (apartment block) has been considered both as residential building and as office building, while the terraced house just as residential. The resume of the investigated cases is shown in Figure 8.

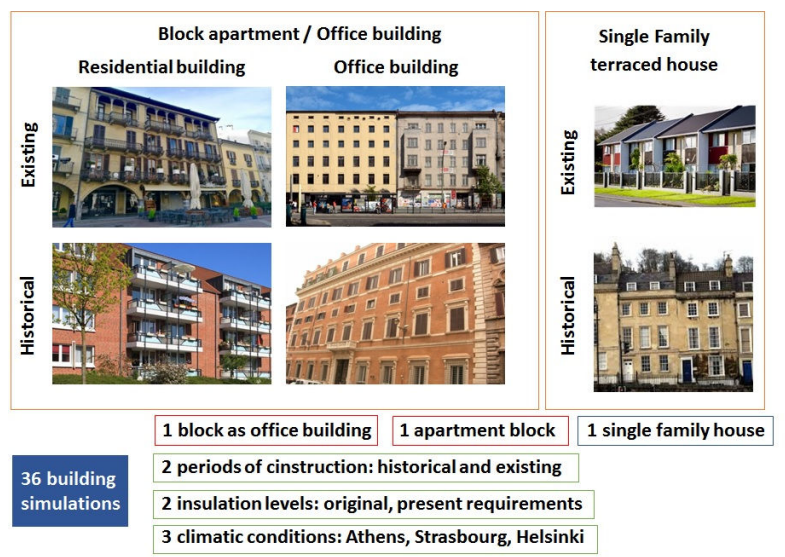

Fig. 8. Resume of the cases which have been examined.

In the case of residential building the heating has been considered on for 13 hours per day all days. In the office buildings the heating has been considered on for 10 hours, without operation in the week-ends.

Sensible heat gains have been assumed according to EN ISO 13790 [9] considering an average of 3 people in the dwellings and a combination of appliances which differs from residential case to office case.

Latent loads have been considered according to ASHRAE 90 [10] which lead to consider as gain the people in the offices and in the residential buildings the combination of people and various activities in the house.

As for the ventilation rates, the baseline has been fixed equal to $0.4 \mathrm{ACH}$ for infiltration rate in all models of existing and historical buildings, while in renovation cases the infiltration rate has been fixed to $0.1 \mathrm{ACH}$ due to the better tightness of the buildings obtained with the installation of new windows. In case of retrofit solutions, flow rate has been fixed according to EN 15251 [11] as shown in Table 3.

Table 3. Fresh air flow rate by mechanical ventilation in retrofitted solutions [ACH]

\begin{tabular}{|c|c|c|c|}
\cline { 2 - 4 } \multicolumn{1}{c|}{} & Case & Historical & Existing \\
\hline Residential & All cases & 0.48 & 0.60 \\
\hline $\begin{array}{c}\text { Non } \\
\text { residential }\end{array}$ & $\mathbf{7 0 ~ \mathbf { ~ } ^ { \mathbf { 2 } }}$ & 0.72 & 0.70 \\
\cline { 2 - 4 } & $\mathbf{9 0} \mathbf{~ m}^{\mathbf{2}}$ & 0.91 & 0.88 \\
\hline
\end{tabular}

Hence for the apartment blocks 2 cases (residential and not) for four types of building envelopes have been considered, i.e. 8 cases. For the terraced house only residential building has been considered with four types of building envelopes, i.e. 4 cases. The overall 12 cases have been examined for the 3 locations, thus leading to 36 cases. Steady state calculation method EN12831 [12] has been applied to determine the peak power for heating, while dynamic simulations have been implemented using the software TRNSYS [13]. 


\section{Results}

Results are shown for the three climates Athens (Figure 9) Strasburg (Figure 10) and Helsinki (Figure 11). In all cases the cooling energy has been calculated considering both the sensible and the latent loads.

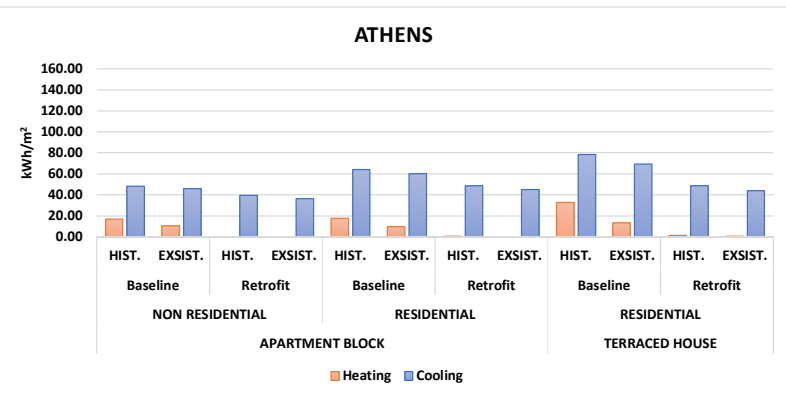

Fig. 9. Energy demand for heating and cooling for Athens

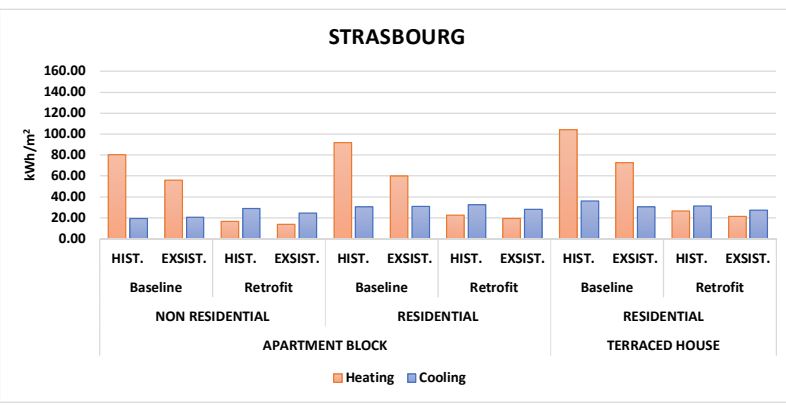

Fig. 10. Energy demand for heating and cooling for Strasbourg.

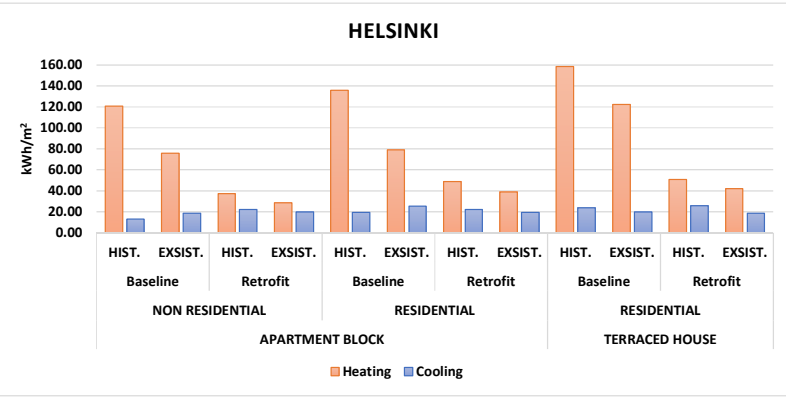

Fig. 11. Energy demand for heating and cooling for Helsinki.

As can be expected, energy demand of the office buildings is lower than the energy demand of the residential buildings, due to the higher number of hours the heating/cooling system is operating.

In the baseline cases (i.e. in case the transmittance of the buildings are the ones reported in Table 2), except Athens, in mild and cold climates the heating energy demand in buildings is dominant. On the contrary, when the buildings are retrofitted in Strasbourg the energy demand for heating and cooling are similar. This is important because in sizing the ground heat exchangers the most critical condition could be the summer, since in the cooling period the energy which has to be delivered into the ground has to take into account the energy of the compressor, while in heating conditions the energy which has to be extracted by the ground is the energy of the building minus the energy of the compressor.

The specific energy demand of the terraced house is higher than the apartment blocks due to the high losses of the buildings: $\mathrm{S} / \mathrm{V}$ is $0.97 \mathrm{~m}^{-1}$ in the case of terraced house and $0.56 \mathrm{~m}^{-1}$ in the case of the apartment block. When looking at the overall energy demand, the apartment block buildings, as average on all climates, have 7 times the energy demand of the terraced house in heating conditions and about 8 times the energy demand for cooling.

\section{Conclusions and discussion}

The paper presents a work in the frame of the H2020 project GEO4CIVHIC, whose aim is to increase the use of GSHP in the built environment of buildings' retrofit. To generalize the results and show stakeholders how to increase the use of geothermal energy inside the cities, GSHP solutions in some typical cases have been shown. For this purpose, it is necessary to define archetypes which may represent the most frequent cases inside urban areas. These archetypes have to be examined in terms of geometry, thermal properties of the envelope, type of use, type of HVAC installed. Based on the different possible strategies of retrofit, both shallow and deep retrofit have to be examined.

The paper reports the first results of this work. The methodology for selecting the archetypes has been shown, identifying two types of linear buildings as representative of the urban context. The first one is a multi-user building, named apartment block. It consists of 5 storeys with 4 units per floor and it has been examined both as residential and office building. The second typology is a single-user building, named terraced house, which has been considered just residential.

A further subdivision has been made in order to consider the construction period, defining as "historic" buildings built before 1960 and existing buildings built after 1960 . For these two types of buildings both current and postretrofit envelopes have been considered. As for the definition of geometrical parameters and thermal properties of the envelope the database TABULAEPISCOPE has been used. For the retrofitted solution a survey on the most typical required values for the envelope under refurbishment in the different countries has been considered.

As for the climates, three climatic locations have been considered: Athens (warm climate), Strasbourg (average climate) and Helsinki (cold climate).

Overall 36 dynamic simulations have been run to determine the heating and cooling energy demands as well as the peak power for heating and cooling. For cooling energy demands sensible and latent loads have been calculated.

The database of energy demands and peak loads will be used for sizing the GSHP in the different archetypes in order to get a cost-benefit analysis. The database of the 
energy demands of the buildings will be made available and could be used by other parties for other purposes.

\section{Acknoledgements}

This work has received funding from the European Union's Horizon 2020 research and innovation program under grant agreement No. 792355.

\section{References}

1. http://geo4civhic.eu/ (last seen: 15/01/2019)

2. I. Ballarini, S.P. Corgnati, V. Corrado, Use of reference buildings to assess the energy saving potentials of the residential building stock: The experience of tabula project, Energy policy 68, 273284 (2014).

3. FprEN 16883:2016. Conservation of cultural heritage - Guidelines for improving the energy performance of historic buildings

4. EN 15898:2011. Conservation of cultural property Main general terms and definitions

5. M. De Carli, A. Bernardi, M. Cultrera, G. Dalla Santa, A. Di Bella, G. Emmi, A. Galgaro, S. Graci, D. Mendrinos, G. Mezzasalma, R. Pasquali, S. Pera, R. Perego, A. Zarrella, A Database for Climatic Conditions around Europe for Promoting GSHP Solutions, Geosciences (Switzerland) 8 (2), February 2018.

6. EN 14825:2016. Air conditioners, liquid chilling packages and heat pumps, with electrically driven compressors, for space heating and cooling - Testing and rating at part load conditions and calculation of seasonal performance.

7. Rasmussen B., Machimbarrena M., COST Action TU0901 - Building acoustics throughout Europe Volume 1: Towards a common framework in building acoustics throughout Europe (2014) http://www.costtu0901.eu/tu0901-e-books.html (last seen 15/01/2019)

8. Application of Energy Performance Indicators for Residential Building Stocks Experiences of the EPISCOPE project (Deliverable D4.1b) March 2016.

9. EN ISO 13790:2008. Energy performance of buildings - Calculation of energy use for space heating and cooling

10. ASHRAE 90 2016. Energy standard for buildings except low-rise residential buildings

11.EN 152512007. Indoor environmental input parameters for design and assessment of energy performance of buildings addressing indoor air quality, thermal environment, lighting and acoustics

12. EN12831 2017. Energy performance of buildings. Method for calculation of the design heat load. Space heating load

13. S. A. Klein et al., TRNSYS 18: A Transient System Simulation Program, Solar Energy Laboratory, University of Wisconsin, Madison, USA (2017) http://sel.me.wisc.edu/trnsys (last seen 15/01/2019) 